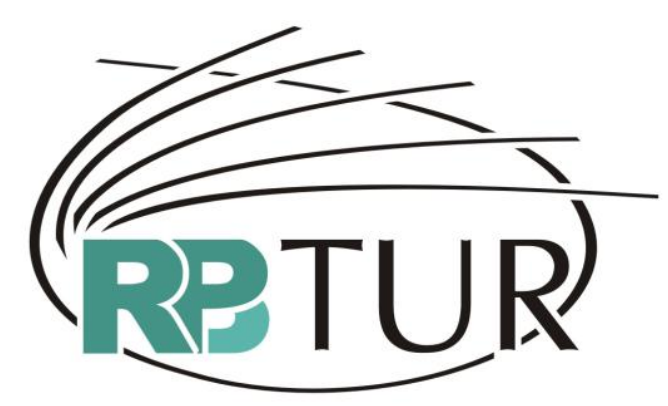

REVISTA BRASILEIRA DE PESQUISA EM TURISMO

\title{
POLÍTICA DE APOIO À CAPTAÇÃO DE EVENTOS INTERNACIONAIS NO BRASIL: ANÁLISE DO RANKING ICCA ENTRE 2003 E 2009
}

\author{
POLICIES FOR SUPPORTING INTERNATIONAL EVENTS \\ PROMOTION IN BRAZIL: ICCA RANKING ANALYSIS FROM \\ 2003 TO 2009
}

\begin{abstract}
POLÍTICA DE APOYO A LA ORGANIZACIÓN DE EVENTOS INTERNACIONALES EN BRASIL: ANALISIS DEL RANKING ICCA ENTRE 2003 Y 2009
\end{abstract}

Lais Carneiro $^{1}$

Resumo: O artigo analisa a relação entre o constatado aumento do número de eventos internacionais sediados no Brasil no período de 2003 a 2009, segundo o ranking da International Conference and Convention Association (ICCA), e a então implantada política federal de apoio à captação de eventos pela EMBRATUR. A metodologia do trabalho, essencialmente qualitativa, consistiu em levantamento de dados secundários aliado à pesquisa de campo por meio de entrevistas pessoais com gestores públicos da política na EMBRATUR e a questionários junto aos representantes dos Conventions Bureaux para avaliar a opinião daqueles que potencialmente se beneficiam da política e que auxiliam em sua implementação. Observou-se que, tanto na opinião institucional quanto na dos parceiros na implementação, a política de apoio figura, dentre outros motivos, como fator colaborador para o aumento do número de eventos internacionais sediados no Brasil neste período.

Palavras chave: Turismo. Políticas públicas. Eventos internacionais. Embratur. Convention Bureaux. Brasil.

Abstract: In this article relation between the amount of international events held in Brazil from 2003 to 2009 according to the International Conference and Convention Association (ICCA) ranking and the recent EMBRATUR federal policy for supporting events organization is analyzed. It is a qualitative research based upon secondary data and field research including interviews with EMBRATUR managers responsible for

${ }^{1}$ Bacharel em Turismo. Especialista em Gestão de Negócios e Consultoria em Turismo pela Universidade de Brasília (UnB). Técnica em Congressos, Negócios e Incentivo do Instituto Brasileiro de Turismo (EMBRATUR). Email: lais.martins@gmail.com 
policies as well as questionnaires applied to heads of Convention Bureaux who benefit from that policy and help implementing it. The outcome is that in the opinions of both sectors supporting policy is one of the factors that helped bring more international events to Brazil.

Keywords: Tourism. Public policy. International events. EMBRATUR. Convention Bureaux. Brazil.

Resumen: El artículo analiza la relación entre el aumento constatado del número de eventos internacionales realizados en Brasil de 2003 a 2009, según el ranking de la International Conference and Convention Association (ICCA), y la entonces implantada política federal de apoyo a la captación de eventos por la EMBRATUR. Se trata de una investigación cualitativa basada en datos secundarios e investigación de campo, con entrevistas a gestores públicos encargados de la política de la EMBRATUR y cuestionarios a los directivos de los Conventions Bureaux para evaluar su opinión. Se observó que en la opinión de ambos sectores la política de apoyo figura entre los motivos coadyuvantes para el aumento del número de eventos internacionales sedeados en Brasil en este período.

Palabras clave: Turismo. Políticas públicas. Eventos. EMBRATUR. Convention Bureaux. Brasil.

\section{Introdução}

Observa-se no Brasil, no mesmo período em que a política de apoio à captação de eventos internacionais foi implantada, um aumento nos eventos internacionais sediados no país que atendem aos critérios da International Conference and Convention Association (ICCA). Entre os critérios adotados pela associação, o evento deve ter um número mínimo de 400 participantes, deve estar em sua terceira edição (no mínimo), ser itinerante e já ter passado por três países diferentes, ser técnico-científico e não ser corporativo ou de caráter competitivo (ICCA, 2010).

Traçando uma curta série temporal, em 2003, o Brasil estava em 190 lugar com apenas 62 eventos internacionais que ocorriam em 22 municípios. Quando esta política foi criada, o seu objetivo era posicionar o Brasil entre os dez principais destinos para a realização de eventos internacionais em 2010 pelo ranking ICCA. Porém, este objetivo foi alcançado já em 2006 conquistando o sétimo lugar no ranking com 207 eventos passando a ocorrer em 35 municípios, tornando-se também o primeiro país latino-americano a estar entre os 10 primeiros países que mais sediam eventos internacionais nos critérios estabelecidos pela ICCA. A posição do Brasil entre os dez primeiros se 
consolidou em 2007, com 209 eventos, em oitavo lugar. Já em 2008, voltou para a sétima posição com 254 eventos. Em 2009 mais uma vez, em sétimo lugar com 293 eventos (BRASIL, 2010).

Inicialmente, pode-se não compreender a relação entre os dois ocorridos. Assim, este trabalho tem como objetivo investigar a participação da política de apoio à captação aos eventos internacionais do Governo Federal para o aumento do número de eventos dentro dos critérios da ICCA, sediados no Brasil no período de 2003 a 2009.

Pode-se compreender este objetivo dentro do espectro de avaliação de políticas públicas. Esta etapa pode ser destinada a melhorar os resultados, ou a fornecer elementos para uma nova intervenção e para o aprimoramento de políticas e programas ou ainda pode ser parte da prestação de contas e da responsabilização dos agentes estatais (FARIA, 2005, p.97). A avaliação de uma política pública como uma das etapas posterior à sua implementação é utilizada para influenciar sua reformulação de forma a adequá-la durante ou após sua implementação (ARRETCHE, 1994). Ela serve não só como mecanismo de controle para verificar se estão funcionando, mas para "dar transparência às ações públicas, democratizar o Estado e a sociedade civil e conhecer as políticas e compreender o Estado em ação [...]" (DRAIBE, 1998. p. 8).

A avaliação da política pública pode ser explicada por meio da relação de casualidade entre ela e os resultados obtidos. A avaliação consiste "na adoção de métodos e técnicas de pesquisa que permitam estabelecer uma relação de casualidade entre um programa $x$ e um resultado $y$, ou ainda, que na ausência do programa $x$ não teríamos o resultado $y$ (FIGUEIREDO; FIGUEIREDO, 1986). É o que se pretende com a presente pesquisa, ou seja, analisar, a partir do olhar dos atores envolvidos, se o aumento significativo dos eventos no período de 2003 a 2009 tem relação com esta política.

Para tanto, este artigo foi estruturado em um referencial teórico que trata de políticas públicas de turismo no Brasil e o papel da captação de eventos seguido por uma seção de métodos. Logo após, são expostos os 
resultados da pesquisa, organizados em três tópicos: fatores atribuídos ao aumento do número de eventos, contribuição da política de apoio à captação e sucesso da captação. Para finalizar, são tecidas as considerações finais.

\section{Políticas públicas de turismo no Brasil e captação de eventos}

Políticas públicas são "ações do Estado orientadas pelo interesse geral da sociedade" (BARRETTO; BURGOS; FRENKEL 2003, p.33). São "o Estado em ação [...] implantando um projeto do governo, através de programas, de ações voltadas para os setores específicos da sociedade" (HOFLING, 2001). A política pública permite fazer uma diferenciação entre a intenção de realizar algo e o que efetivamente se realiza envolvendo vários atores e níveis de decisão, apesar de ser materializada pelos governos e não se restringir a participantes formais.

Em poucas palavras, as políticas públicas estão altamente relacionadas com planejamento, pois a organização de um setor deve ser resultado de um processo contínuo de planejamento. A política não é só um instrumento do planejamento e sim sua essência (CRUZ, 2002).

No turismo, "o papel das políticas públicas deveria ser o de propiciar o desenvolvimento harmônico dessa atividade" (BARRETTO; BURGOS; FRENKEL, 2003, p.33). Assim, a política de turismo é "o conjunto de fatores condicionantes e de diretrizes básicas que expressam os caminhos para atingir os objetivos globais para o Turismo do país [...]" (BENI, 2006, p.103).

A participação do Governo neste contexto pode se dar mediante a participação, o controle ou a indução. Quanto à política de captação de eventos, esta pode ser considerada na modalidade de indução, pois o Estado atua como orientador do comportamento dos agentes de mercado, que pode ser feito por meio da concessão de incentivos para investimentos (FERRAZ, 1992). Assim, o Estado cria a política para fornecer subsídios e orientações a parceiros para captação destes eventos não atuando diretamente como executor nem regulador dessa atividade na iniciativa privada. 
A importância das políticas públicas de turismo foi negligenciada no Brasil por muito tempo pelos poderes públicos, e somente a partir da década de 1990 iniciou-se a organização do setor do turismo, reestruturando os organismos oficiais e implementando programas nacionais e regionais com a instituição da Política Nacional de Turismo. Esta política foi relevante e alcançou visibilidade, pois era orientada para organizar o setor turístico no âmbito federal. Foi criada uma cartilha acessível a todos, intitulada "Política Nacional de Turismo - Diretrizes e Programas (1996-1999)".

No entanto, com a criação do Ministério do Turismo em 2003, o governo passou a agir ativamente no setor turístico estabelecendo a criação de um Plano Nacional de Turismo para reger a atividade no país e atribuiu a promoção internacional a sua autarquia. Em entrevista a Massari (2006) para a revista Observatório de Inovação de Turismo, o ex-presidente do Instituto Nacional de Turismo (EMBRATUR), Eduardo Sanovicz, quando perguntado a respeito dos ganhos a mudança de foco deste instituto, afirmou que "entrando nesta disputa do turismo internacional seria possível consolidar um terceiro eixo como possibilidade real, um eixo de desenvolvimento econômico" (MASSARI, 2006, p.2). Complementou ainda que, a partir de um programa eficaz para disputar o mercado internacional, que aumentasse o volume de passageiros para o Brasil, possibilitaria o acesso do país à moeda estrangeira.

A EMBRATUR tem suas atividades orientadas pelo Plano Aquarela e a política de apoio à captação se encaixa dentro de um programa específico deste Plano; foi criada para promover a imagem do Brasil no exterior e conseqüentemente estimular o aumento do número de turistas estrangeiros bem como o aumento da permanência destes no país. Esta política prevê a participação de parceiros e, vai além, pois determina que a participação seja

2 A política que está sendo enfocada neste trabalho encontra-se inserida no programa de Promoção, Marketing e apoio à Comercialização em Outros Mercados do Plano Aquarela, citado anteriormente. Além deste, o Plano possui mais três programas: 1) Promoção, Marketing e apoio à comercialização no Mercado Europeu; 2) Promoção, Marketing e apoio à Comercialização no Mercado Norte Americano; 3) Promoção, Marketing e apoio à Comercialização no Mercado Latino Americano (BRASIL, 2009). 
imprescindível para a realização das ações e do alcance dos objetivos estabelecidos no referido Plano (BRASIL, 2009).

Este instrumento foi elaborado, portanto, como forma de estimular e apoiar as organizações a captarem eventos internacionais, obviamente dentro dos critérios estabelecidos na referida política. Ademais, é um meio de priorizar os eventos a serem apoiados devido à alta demanda ultrapassando a possibilidade de atendimento da EMBRATUR. Para tanto, foram estabelecidos critérios com vistas a maximizar as oportunidades e resultados. As ações de apoio aos eventos de captação que podem ser realizadas vão desde uma simples produção de material, até a celebração de convênios (BRASIL, 2009).

Esta política de apoio visa essencialmente o segmento de negócios e eventos que pode ser definido como "[...] o conjunto de atividades turísticas decorrentes dos encontros de interesse profissional, associativo, institucional, de caráter comercial, promocional, técnico, científico e social" (BRASIL, 2005, p.46). Este conceito foi trazido pelo Ministério do Turismo - MTur, que separou, em partes, a oferta turística com seus respectivos elementos de identidade. Conforme esta definição foram propostos onze segmentos ${ }^{3}$ além do supracitado.

Este segmento, também de acordo com o Ministério do Turismo (BRASIL, 2008), é estratégico, pois tem a capacidade de minimizar os efeitos da sazonalidade independentemente da existência ou não de atrativos naturais e culturais. Outra característica é a transversalidade por sua abrangência em outros segmentos como é o caso de eventos culturais que também está ligado ao segmento de turismo cultural, por exemplo. O mesmo acontece com os eventos esportivos que atingem o segmento de turismo de esportes. Além da transversalidade, o turismo de negócios e eventos proporciona alta rentabilidade devido ao turista apresentar maior gasto médio, permanecer mais tempo e retornar mais vezes ao destino.

\footnotetext{
3 Turismo social, ecoturismo, turismo cultural, turismo de estudos e intercâmbio, turismo de esportes, turismo de pesca, turismo náutico, turismo de aventura, turismo de sol e praia, turismo rural e turismo de saúde.
} 
O citado segmento é considerado um dos que mais cresce no turismo, razão pela qual os governos têm utilizado os eventos como estratégia de marketing do destino em prol do desenvolvimento econômico de seus países. "Organizar ou sediar eventos tornou-se uma forma de os países promoverem a sua imagem, de se apresentarem ao mundo e gerarem lucros para a cidade ou região anfitriã." (EMBRATUR; FGV, 2009, p.8). Ainda de acordo com esta pesquisa, a perspectiva é que o número de eventos aumente significativamente e conseqüentemente a concorrência por sediá-los no país.

É neste contexto que a captação e a promoção de eventos contribuem para tornar um país mais competitivo frente aos demais. Devido à crescente relevância das viagens para participação nos diversos tipos de eventos, as despesas já são contabilizadas como consumo turístico, pois o visitante de eventos utiliza a infra-estrutura e consome produtos e serviços turísticos.

O turismo de eventos está relacionado ao turismo de negócios, pois esses se tornam, em certos momentos, o objetivo principal de uma viagem, motivando deslocamento de pessoas. "Para a EMBRATUR, a captação de eventos é uma estratégia vital para o turismo brasileiro, aumentando a visibilidade do país no exterior e atraindo turistas cujos gastos médios são elevados" (EMBRATUR; FGV, 2009; p.9).

A captação de eventos tem como uma de suas principais características o fato de movimentar a economia local, promovendo a visita de turistas de alto poder aquisitivo, além de posicionar o Brasil internacionalmente, por meio de parcerias com entidades brasileiras filiadas a órgãos internacionais, convention \& visitors bureaux, secretarias de turismo, órgãos governamentais e instituições não governamentais e a iniciativa privada, no intuito de identificar e captar os eventos de maior importância para o país.

As ações possíveis de serem feitas em parceria com a EMBRATUR visam essencialmente a divulgação do Brasil como sede dos eventos internacionais e consistem em apoios a cidades. Dessa forma, é imprescindível partir delas o intuito de captar determinado evento. No entanto, não deixa der ser do interesse do Instituto em obter êxito, pois significa alcançar o objetivo 
delineado no Plano Aquarela de trazer mais turistas para o país e conseqüentemente mais divisas.

\section{Metodologia}

Esta pesquisa tem caráter qualitativo e descritivo, já que "procura descrever fenômenos ou estabelecer relação entre as variáveis" (DENCKER, 1998, p.124).

O estudo partiu da pesquisa bibliográfica, para posteriormente realizar uma pesquisa de campo a fim de responder a pergunta que foi proposta. Na pesquisa de dados primários, foram estipuladas duas etapas complementares: realização de entrevistas para apurar a opinião institucional e aplicação de questionários junto àqueles que se utilizam da política. Estas duas etapas foram empreendidas para que se pudessem apurar dados mais robustos e complementares, pois se constatou que as entrevistas seriam insuficientes uma vez que limitariam a apurar a opinião institucional.

A primeira etapa contou com entrevistas porque elas permitem "obter dados relevantes e significativos para o estudo que está sendo realizado e [...] permite obter maior quantidade de respostas" (SCHLÜTER, 2003, p.107). Optou-se por uma entrevista semi-estruturada, pois "é uma comunicação verbal entre duas pessoas, com um grau de estruturação previamente definido, cuja finalidade é a obtenção de informações de pesquisa" (DENCKER, 1998, p.137). O roteiro foi composto por seis perguntas, feitas presencialmente para permitir a interação com o entrevistado ou até mesmo a complementação da pergunta quando necessário.

Foram selecionados intencionalmente indivíduos "representativos do fenômeno que estuda" (SCHLÜTER, 2003. p.92), pois já se tinha prévio conhecimento daqueles que trabalham com a política, como técnicos e gestores. Foram entrevistados quatro sujeitos que trabalham com a política de apoio do Governo. Os respondentes foram: um técnico da área de captação que trabalha há três anos na EMBRATUR, um técnico de promoção que 
trabalha nesta área há quatro anos, o gerente da coordenação responsável que trabalha neste Instituto há mais de sete anos e o gestor do Plano Aquarela que trabalha nesta função há mais de dois anos, mas possui mais tempo no Instituto.

A segunda etapa consistiu em aplicar um questionário junto a representantes dos Conventions Bureaux de cada cidade ou região, pois são os principais parceiros e beneficiários desta política. Foram elaboradas 8 perguntas, sendo duas fechadas ou dicotômicas, duas perguntas estimativas, ou seja, que indica o grau de intensidade e quatro abertas. Os respondentes foram delimitados a partir da listagem de CVBX pertencente ao banco de dados da EMBRATUR. Foram selecionados aqueles constantes nas 14 primeiras posições no ranking ICCA das cidades brasileiro de 2009, pois são as que possuem maior representatividade e por serem também os CVBx mais atuantes e que mais realizam ações com a EMBRATUR e de certa forma contribuem mais com a captação e promoção de eventos. O número de respondentes foi estimado em razão da viabilidade de tempo e recursos para execução desta pesquisa. É importante ressaltar que aqueles que responderam a este questionário foram os responsáveis pela área de captação de cada Convention, ou área equivalente, com muito tempo de experiência.

Para compilação e análise dos dados foram utilizadas formas diferentes para os questionários e para as entrevistas. Para os primeiros, analisou-se por questão respondida agrupando-se repostas semelhantes a fim de estabelecer uma ligação entre as variáveis dos dados obtidos, formularam-se gráficos para melhor visualização e compreensão da freqüência das respostas e das médias.

Para as entrevistas, devido ao pequeno número de participantes, baseouse na análise do discurso, pois de acordo com Davel e Silva (2005) a pesquisa, de natureza qualitativa baseia-se na análise de discurso obtido por meio de entrevistas semi-estruturadas realizadas junto aos representantes de entidades responsáveis. Para tanto, trabalhou-se com a apresentação e discussão da idéia principal de cada questão e de cada entrevistado 
aproximando as respostas semelhantes e ressaltando aquelas diferentes ou complementares.

Os resultados da pesquisa foram agrupados de acordo com a perspectiva dos usuários da política, seguida pela percepção de seus gestores. Os resultados são discutidos ao redor de três temas: (1) fatores atribuídos ao aumento do número de eventos, (2) contribuição da política de apoio à captação e (3) sucesso da captação.

\section{Fatores ligados ao aumento do número de eventos no Brasil}

A política de apoio à captação foi citada nos questionários três vezes como mais importante, sendo também citada pelo menos uma vez em cada grau de importância. Os outros fatores mais mencionados foram: profissionalismo, alimentação do banco de dados para o ranking da ICCA, imagem do Brasil e infra-estrutura.

Infere-se que a política de apoio foi uma constante dos itens que contribuíram para o aumento do número de eventos entre 2003 a 2009, pois foi lembrada por todos os respondentes e em todos os graus de relevância sendo que $1 / 3$ destes foram atribuídos como mais importante. Este saldo foi obtido sem que se perguntasse diretamente a contribuição da política para o aumento do número de eventos. Isto reflete que aqueles que se utilizam deste instrumento atribuem parte da evolução do número de eventos à política.

Levando-se em conta que para a pergunta um do questionário eram sugeridas quatro respostas relacionadas, foram listados 33 motivos distribuídos nos grupos explicados anteriormente. Constatou-se que os CVBX apontaram em 12 itens a política de apoio à captação pela EMBRATUR, mencionados de diversas formas diretas e indiretas. Foram detectadas ainda três questões atreladas a profissionalismo, seis à imagem do Brasil e uma à coleta de dados para o ranking ICCA que contribuíram para o aumento do número de eventos como ações apoiadas por esta autarquia. Ressalva-se que os fatores citados podem estar ligados ao mesmo tempo a mais de um grupo 
pré-estabelecido (políticas de apoio, profissionalismo, imagem do Brasil e infra-estrutura), porém para fins de entendimento e compilação de dados, contabilizou-os em apenas um grupo.

Depreende-se, portanto, que a EMBRATUR apoiou quase metade destas ações e muitas delas estão relacionadas direta ou indiretamente à política de apoio. Pode-se afirmar que os fatores relacionados ao profissionalismo e à imagem do Brasil estão de alguma forma relacionados com o trabalho da EMBRATUR, que abrange outras áreas de atuação da autarquia. As ações ligadas ao ranking ICCA são desenvolvidas pela mesma coordenação responsável pela política de apoio à captação, até mesmo pela natureza da atividade, pois se refere, de certa forma, à captação de eventos internacionais.

A opinião institucional ainda em relação a esta questão foi prioritariamente conferida como responsabilidade em parte às ações do Governo, em especial àquelas voltadas à política de apoio à captação. Tal fato vai ao encontro da opinião dos parceiros acima explicitada.

Dentre os fatores mais importantes dos listados acima, os entrevistados citaram o apoio aos CVBx fortalecendo a parceria público-privada. Destacou-se também a importância da sensibilização e conscientização do Governo local e da comunidade para a necessidade de reconhecer o que um evento representa para a cidade, estado ou região. Dois entrevistados foram bem pontuais, um deles elegendo a profissionalização e imagem do país; outro, a parceria com as entidades representativas das mais diversas categorias profissionais, entre outros parceiros, para a captação e promoção desses eventos para o Brasil. Por fim, um deles declarou que devido à importância de cada item ser definida com o foco do evento, não acreditou ser possível, em princípio, elencar um fator como mais importante.

Fazendo uma comparação entre as opiniões dos parceiros e a institucional, infere-se que a política teve sua participação no contexto analisado, em ambos os casos. Na primeira observou-se que ela dividiu o espaço com outros motivos, porém com certo destaque. 


\section{Contribuição da Política de Apoio à Captação}

O grau de contribuição da política de uma forma geral para o aumento do número de eventos foi alto, pois houve maior concentração de notas acima de 8. Observou-se que dois dos respondentes atribuíram nota 10, dois nota 9, três nota 8 , um nota 6 e outro nota 4, resultando em uma nota média de 8 pontos. Isso indica que a política foi bem avaliada quanto à se constituir como um instrumento de apoio e fator de contribuição para o aumento do número de eventos. Porém, como explicado anteriormente, isto era previsto em decorrência de uma afirmação instintiva em relação a uma pergunta que investiga se determinada política que visa alcançar certo objetivo ajudou a alcançá-lo.

No entanto, as médias obtidas individualmente por cada forma de apoio ratificaram o resultado anterior, pois todas obtiveram médias altas, acima de 7. Os citados como mais importante para a captação dos eventos apoiados pela EMBRATUR foram a carta de apoio, convênio, material promocional, o dossiê de candidatura e material específico. De maneira geral, as notas atribuídas a todas as formas de apoio se concentraram em altos índices, o que reforça a boa avaliação da política. Houve algumas notas mais baixas, mas em casos isolados.

Quanto à opinião institucional em relação às formas de apoio consideradas mais importantes, verificou-se que a maioria dos entrevistados alegou que não se pode eleger uma isoladamente, pois elas se complementam e, além disso, dependem do formato de cada evento. Porém, foram ressaltadas as seguintes formas de apoio: representante na defesa de candidatura e nas visitas de inspeção, com o argumento que são oportunidades únicas, tendo em vista que se trata de momentos em que o poder de convencimento se dará de forma mais dinâmica e verdadeira. É quando se pode mostrar o que o país tem para oferecer no que tange ao seguimento de turismo de negócios e eventos. Foram eleitos também o bidding book, a presença de representante e o convênio. O material específico foi 
considerado essencial ao processo de captação de eventos internacionais bem como a carta de apoio.

Quando questionados se estas ações foram determinantes para a decisão de sediar os eventos no Brasil, sete entrevistados responderam que sim, porém os outros dois responderam não. Tal proporção demonstra mais uma vez que os parceiros, em sua maioria, consideram a política, através de suas formas de apoio, como instrumento de apoio na hora de captar eventos internacionais para o país.

Além disso, os eventos captados com o apoio desta política, segundo os entrevistados, influenciaram outros eventos a ocorrerem no Brasil, refletido na mesma freqüência do item anterior, em uma proporção de 7 (sim) para 2 (não).

A opinião institucional acerca da influência da política para que outros eventos ocorressem no Brasil reforçou a opinião dos parceiros. Um dos entrevistados alegou que uma política consolidada mostra que o país possui um plano e estrutura para apoiar a realização de eventos transmitindo segurança para o país sediar eventos. Um terceiro entrevistado explicou que a política possibilitou que alguns eventos importantes fossem captados para 0 Brasil, resultando em um diferencial na visibilidade do país. Um entrevistado atribuiu, à política e ao trabalho realizado pela EMBRATUR e seus parceiros, 0 Brasil ocupar atualmente o sétimo lugar no ranking ICCA, entre os dez países que mais realizaram eventos internacionais conforme os critérios daquela entidade; isso também dá visibilidade e credibilidade ao país enquanto destino para o turismo de negócios e eventos, e o credencia no mercado internacional. Em suma, todos afirmaram que a participação do Governo no apoio as candidaturas influencia o evento a ocorrerem no Brasil, pois a participação do governo oferece credibilidade, segurança, organização, profissionalismo e comprometimento do país que se candidata a sediar um evento internacional. 


\section{Sucesso da captação}

Em relação aos motivos mais relevantes para o sucesso da captação, do ponto de vista dos parceiros, foram apontados fatores ligados ao posicionamento político das entidades brasileiras perante as estrangeiras como influência e prestígio na entidade internacional e número de associados.

As razões de política interna da entidade, como fatores de rotatividade do evento dentre as diversas regiões do mundo, e os objetivos da entidade internacional são determinantes. São levados em conta fatores como: se a entidade tem o intuito de realizar o evento na América Latina e mais especificamente no Brasil, ou se ela tem o interesse de aumentar o número de associados nessa região, ou ainda se ela gostaria de ter a oportunidade de ver in loco o que vem sendo feito no Brasil. Este último fator está relacionado muito à imagem do país-candidato que também é considerado importante na hora da decisão. Pode estar ligado também à organização, envolvimento e articulação junto aos tomadores de decisão, o país nunca ter sediado o evento, boa condições para a realização como infra-estrutura, contando com centro de convenções e rede hoteleira bem estruturados e uma boa defesa de candidatura.

Outra variante mencionada é a questão da exigência que muitas entidades fazem de apresentar garantia financeira que na maioria dos casos as entidades proponentes brasileiras não apresentam. O convênio foi citado como uma forma de sucesso para a captação. Foram citados também: a segmentação, o foco em resultados, uma preparação de dossiês de candidatura em conjunto com a entidade brasileira, cumprindo os prazos, apresentando material gráfico de qualidade e informativo e uma boa apresentação, quando exigida.

Do ponto de vista institucional, foram elencados os fatores como a preparação e foco da equipe na missão de vender as cidades brasileiras para sediar eventos internacionais. Além disso, explicou-se que o investimento dos Estados nos centros de convenções e da iniciativa privada na hotelaria 
contribui para este sucesso. É importante também que se tenha conhecimento e entendimento das necessidades do evento e das entidades promotoras. Além disso, falou-se da importância de um material de qualidade e disponível em outros idiomas, que apresentem corretamente as informações e os aspectos relevantes e positivos do Brasil. Foi mencionado que é necessário tornar possível e plausível a realização de um evento no Brasil para os seus organizadores sendo necessário que as cidades tenham a estrutura satisfatória para receber estes eventos, além de profissionais capacitados para este tipo de turismo, que envolve muito mais do que apenas sua realização. Foi afirmado também que é imprescindível o entrosamento entre as forças locais e uma boa estratégia de candidatura.

Já os motivos apresentados para o insucesso englobam os altos custos da realização do evento no Brasil, devido à distância e dificuldade para viabilização orçamentária do evento (em relação à obtenção de patrocínios privados e de apoios governamentais). A opinião institucional mencionou também o não cumprimento das propostas apresentadas, atrapalhando a imagem do país, falta de material adequado, desconhecimento da importância do segmento a ser captado, insegurança, além de fatores relacionados à infraestrutura como equipamentos obsoletos, hotéis, centros de convenções sem estrutura para receber os eventos. Complementarmente a esta resposta, outro entrevistado se referiu à desorganização e falta de preparo por todas as partes envolvidas neste processo de captação de eventos.

Observou-se que as opiniões convergem no que tange à política de apoio estar dentre outros motivos, como fator colaborador para o aumento do número de eventos internacionais sediados no Brasil constatado no período de 2003 a 2009. Notou-se também que a EMBRATUR foi indicada como apoiadora de várias destas ações. Diante disto, a maioria dos respondentes afirmou que a política é determinante para a captação do evento e que é capaz de influenciar outros eventos a ocorrerem no Brasil. A opinião institucional foi unânime em atribuir este acréscimo, em parte, à política de apoio à captação. 


\section{Considerações Finais}

O objetivo desta pesquisa foi analisar a relação entre a política de apoio à captação de eventos internacionais para o Brasil e o aumento do número de eventos internacionais sediados no país no período entre 2003 e 2009. Para tanto, a metodologia utilizada foi não somente a pesquisa documental e bibliográfica, como também a pesquisa de campo como a aplicação de questionários e entrevistas junto a atores sociais relevantes ao tema.

Diante do exposto pelos resultados, infere-se haver uma contribuição da política de apoio à captação de eventos internacionais do Governo Federal, contida no Plano Aquarela, para o aumento do número de evento internacionais sediados no Brasil no período de 2003 a 2009.

No geral, tanto a política como um todo, quanto as suas ações específicas, foram bem avaliadas. Identificou-se também, que muito dos fatores mencionados para este aumento estão de alguma forma ligada a este apoio como a imagem do Brasil, o interesse dos Estados em fazerem parte do ranking ICCA e a segmentação de mercado. Todos os aspectos citados fazem parte dos objetivos do Plano Aquarela e permeiam os objetivos da política, de forma mais pontual e objetiva.

Ainda que haja indícios, a partir dos respondentes, de que a política estudada contribuiu para o aumento do número de eventos internacionais sediados no Brasil entre 2003 e 2009, não se pode, no entanto, mensurar esta contribuição a partir dos dados apurados. Tampouco se pode isolar a política como único fator que favoreceu este incremento.

Entre as limitações da pesquisa, está o baixo índice de retorno dos questionários, a despeito da insistência por parte dos pesquisadores. Ainda, ressalta-se que as entrevistas, apesar de ricas para o trabalho e abordagem do tema, tendem a apresentar vieses institucionais. 


\section{Referências}

ARRETCHE, M. T. da S. Políticas de habitação para baixa renda e de saneamento. Relatório Final. São Paulo, IESP/FUNDAP, 1994. In: RICO. E. M. (Org.) Avaliação de políticas sociais: uma questão em debate. São Paulo: Cortez, 1998. (Subprojeto "Canais de acesso aos fundos públicos na área social", da pesquisa "Balanço e perspectivas do federalismo fiscal no Brasil)

BARRETTO, M. BURGOS, R.; FRENKEL, D. Turismo, políticas públicas e relações internacionais. Campinas: Papirus, 2003

BENI, M. C. Análise estrutural do turismo. 11 ed. São Paulo: SENAC, 2006.

BRASIL. Ministério do Turismo. Eventos internacionais no Brasil - Relatório de resultados 2003 - 2009: desafios para 2020. Brasília, 2010.

BRASIL. Ministério do Turismo. Plano aquarela 2020: marketing turístico internacional do Brasil. Brasília, 2009.

BRASIL. Ministério do Turismo. Turismo de negócios \& eventos: orientações básicas. Brasília, 2008.

BRASIL. Ministério do Turismo. Segmentação do turismo: marcos conceituais. Brasília, 2005.

CRUZ, R. de C.. Políticas de turismo no Brasil: significado, importância, interfaces com outras políticas setoriais. In: SOUZA, M. J. de. (org) Políticas públicas e o lugar do turismo. Brasília: UnB, 2002.

DAVEL, E.; SILVA, J. C. de S. Concepções, práticas e desafios na formação do professor: examinando o caso do ensino superior de administração no Brasil. Organização e Sociedade, Salvador, v.12, n.35. 2005, p. 113-134.

DENCKER, A. de F M.. Métodos e técnicas de pesquisa em turismo. 5.ed. São Paulo: Futura. 1998.

DRAIBE, S. Seminário sobre avaliação de políticas públicas e programas sociais. In: RICO. E. M. (Org.). Avaliação de políticas sociais: uma questão em debate. São Paulo: Cortez, 1998.

EMBRATUR - INSTITUTO BRASILEIRO DE TURISMO; FGV - FUNDAÇÃO GETÚLIO VARGAS. Pesquisa do impacto econômico dos eventos internacionais realizados no Brasil - 2007/2008. Brasília: EMBRATUR/FGV, 2009.

FARIA, Carlos Aurélio Pimenta de. A política da avaliação de políticas públicas. Revista Brasileira de Ciências Sociais, v. 20, n. 59. 2005. Disponível em <http://www.scielo.br/pdf/\%0D/rbcsoc/v20n59/a07v2059.pdf >, acessado em ago. de 2010.

FERRAZ, J. A. Regime jurídico do turismo. Campinas: Papirus, 1992.

FIGUEIREDO, M. F.; FIGUEIREDO, A. M. C. Avaliação política e a avaliação de políticas: um quadro de referência teórica. In: Textos IDESP, n. 15, São Paulo, 1986, mimeo.

HOFLING, E. de M. Estado e políticas públicas sociais. Cadernos Cedes, ano XXI, n. 55, Nov., 2001, p. 30-41.

ICCA - INTERNATIONAL CONGRESS AND CONVENTION ASSOCIATION. Statistics report 2009: International Association Meetings Market - Country and cities rankings. ICCA, maio, 2010. 
MASSARI, C. Entrevista com Eduardo Sanovicz. Revista Acadêmica Observatório de Inovação do Turismo, v.1, n.1, 2006. Disponível em: http://www.ebape.fgv.br/revistaoit/arq/entrevista/ENTREVISTA3.pdf acessado em agosto de 2010.

SCHLÜTER, R. G. Metodologia da pesquisa em turismo e hotelaria. Trad.Tereza Jardini. 2.ed. São Paulo: Aleph, 2003.

Artigo recebido em setembro de 2011.

Aprovado para publicação em novembro de 2011. 